See Article page 25.

\section{Commentary: The devil is in the details}

Joseph S. Coselli, MD, and
Vicente Orozco-Sevilla, MD

The surgical management of thoracoabdominal aortic aneurysm (TAAA) remains a high-stakes endeavor for both surgeon and patient; this includes the technical aspects of this complex procedure and the risk of lifealtering postoperative complications or death, respectively. In recent years, significant strides have been made toward improving outcomes of hybrid and total endovascular repair; the former being an off-label application, and the latter being restricted to the purview of clinical trials as part of physician-sponsored investigational device exemptions. The Crawford classification system defines an extent II TAAA repair as one that extends from the region of the left subclavian artery to the aortic bifurcation and may additionally encompass the iliac arteries; it remains the most challenging and greatest-risk repair of all forms of TAAA. ${ }^{1,2}$ In this issue of JTCVS Techniques, the talented and experienced aortic group from the Department of Cardiac Surgery, St Bartholomew's Hospital, London, United Kingdom, describe their step-by-step approach to the open repair of Crawford extent II TAAA with appropriate detail and well-chosen images. ${ }^{3}$ Importantly, in addition to the specific technicalities with regards to replacing the entire thoracoabdominal aorta with Dacron graft, they provide

From the Division of Cardiothoracic Surgery, Michael E. DeBakey Department of Surgery, Baylor College of Medicine; Department of Cardiovascular Surgery, Texas Heart Institute; and CHI St Luke's Health-Baylor St Luke's Medical Center, Houston, Tex.

Disclosures: This editorial was not funded. Dr Coselli's work is partly supported by the Cullen Foundation. Dr Coselli consults for, receives royalties and a departmental educational grant from, and participates in clinical trials for Terumo Aortic; consults and participates in clinical trials for Medtronic, Inc, and W. L. Gore \& Associates; and serves as a co-investigator for CytoSorbents. Dr Orozco-Sevilla reported no conflicts of interest.

The Journal policy requires editors and reviewers to disclose conflicts of interest and to decline handling or reviewing manuscripts for which they may have a conflict of interest. The editors and reviewers of this article have no conflicts of interest.

Received for publication June 26, 2020; revisions received June 26, 2020; accepted for publication July 2, 2020; available ahead of print July 9, 2020.

Address for reprints: Joseph S. Coselli, MD, One Baylor Plaza, BCM 390, Houston, TX 77030 (E-mail: jcoselli@bcm.edu).

JTCVS Techniques 2020;3:37-8

2666-2507

Copyright (C) 2020 The Authors. Published by Elsevier Inc. on behalf of The American Association for Thoracic Surgery. This is an open access article under the CC BY-NCND license (http://creativecommons.org/licenses/by-nc-nd/4.0/).

https://doi.org/10.1016/j.xjtc.2020.07.002

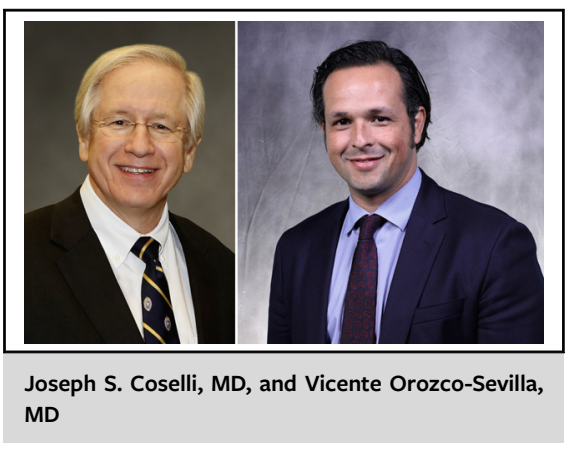

CENTRAL MESSAGE

Repair of Crawford extent II

thoracoabdominal aortic aneu-

rysm is complex and necessitates

the use of multiple adjuncts to

mitigate surgical risk.

a detailed description regarding their use of several surgical adjuncts to mitigate operative risk, including left heart bypass, cerebral spinal fluid drainage, motor-evoked potential monitoring, as well as visceral and renal perfusion. In an extensive and complex operative procedure, such as the in situ replacement of an extent II TAAA, the devil is in the details. Herein, the authors provide clear, concise, and eminently useful descriptions of their approach. Consequently, for those surgeons desiring to pursue such procedures, this manuscript serves a noteworthy contribution to the literature.

It is important to understand that with regards to the spectrum of adjuncts that may be considered for use in extent II TAAA repair, there is substantial variation in how they are regarded. For example, the use of cerebral spinal fluid drainage is well established, in widespread use, and recommended by current aortic guidelines. ${ }^{4,5}$ In contrast, the use of adjuncts such as motor-evoked potential monitoring and visceral perfusion is less established, with the related literature being less dogmatic and without formal recommendation. Consequently, in establishing or evolving a surgical program, detailed descriptions, enhanced by photos and illustrations, such as the authors provide, serve as an essential reference.

A key to providing excellent results to patients undergoing complex, high-risk cardiovascular procedures is the establishment of a surgical program with a dedicated team. The inclusion of committed anesthesiologists, nurses, perfusionists, cardiologists, radiologists, and critical care specialists-who are devoted to perfecting the 
many nuances in the management of these patients-is irreplaceable. Many successful programs make selections among the various options for surgical adjuncts to protect the brain, spinal cord, viscera, and kidneys; they set a course establishing proficiency by following evolutionary, rather than revolutionary, alterations to their overall approach by refining techniques as reliable information becomes available. For the foreseeable future, the continued refinement of protective adjuncts is an area for which maintaining our open operative skills remains crucial.

\section{References}

1. Coselli JS, LeMaire SA, Preventza O, de la Cruz KI, Cooley DA, Price MD, et al. Outcomes of 3309 thoracoabdominal aortic aneurysm repairs. J Thorac Cardiovasc Surg. 2016;151:1323-37.
2. Svensson LG, Crawford ES, Hess KR, Coselli JS, Safi HJ. Experience with 1509 patients undergoing thoracoabdominal aortic operations. J Vasc Surg. 1993;17: 357-68; discussion 68-70.

3. Lopez-Marco A, Adams B, Oo AY. Thoracoabdominal aneruysmectomy: operative steps for Crawford extent II repair. J Thorac Cardiovas Surg Tech. 2020;3:25-36.

4. Erbel R, Aboyans V, Boileau C, Bossone E, Bartolomeo RD, Eggebrecht H, et al. 2014 ESC guidelines on the diagnosis and treatment of aortic diseases: document covering acute and chronic aortic diseases of the thoracic and abdominal aorta of the adult. The task force for the diagnosis and treatment of aortic diseases of the European Society of Cardiology (ESC). Eur Heart J. 2014;35:2873-926.

5. Hiratzka LF, Bakris GL, Beckman JA, Bersin RM, Carr VF, Casey DE Jr, et al. 2010 ACCF/AHA/AATS/ACR/ASA/SCA/SCAI/SIR/STS/SVM guidelines for the diagnosis and management of patients with thoracic aortic disease. A report of the American College of Cardiology Foundation/American Heart Association task force on practice guidelines, American Association for Thoracic Surgery, American College of Radiology, American Stroke Association, Society of Cardiovascular Anesthesiologists, Society for Cardiovascular Angiography and Interventions, Society of Interventional Radiology, Society of Thoracic Surgeons, and Society for Vascular Medicine. J Am Coll Cardiol. 2010;55:e27-129. 